\title{
East African food security as influenced by future climate change and land use change at local to regional scales
}

\author{
Nathan Moore • Gopal Alagarswamy • \\ Bryan Pijanowski • Philip Thornton • Brent Lofgren • \\ Jennifer Olson · Jeffrey Andresen · Pius Yanda · Jiaguo Qi
}

Received: 11 August 2009 / Accepted: 16 May 2011 / Published online: 10 June 2011

(C) The Author(s) 2011. This article is published with open access at Springerlink.com

\begin{abstract}
Climate change impacts food production systems, particularly in locations with large, vulnerable populations. Elevated greenhouse gases (GHG), as well as land cover/land use change (LCLUC), can influence regional climate dynamics. Biophysical factors such as topography, soil type, and seasonal rainfall can strongly affect crop yields. We used a regional climate model derived from the Regional Atmospheric Modeling System (RAMS) to compare the effects of projected future GHG and future LCLUC on spatial variability of crop yields in East Africa.
\end{abstract}

N. Moore
College of Environmental and Resource Sciences, Zhejiang University, Hangzhou, China

N. Moore · G. Alagarswamy · J. Andresen · J. Qi

CGCEO, Michigan State University, 202 Manly Miles Bldg, East Lansing, MI 48823, USA

B. Pijanowski

Department of Forestry and Natural Resources, Purdue University, 195 Marsteller St, FORS203, West Lafayette, IN 47906, USA

P. Thornton

International Livestock Research Institute, PO Box 30709, Nairobi 00100, Kenya

B. Lofgren

Great Lakes Env. Research Lab, 4840 S. State Road, Ann Arbor, MI 48108-9719, USA

J. Olson

Communication Arts and Sciences, Michigan State University, 202 Manly Miles Bldg,

East Lansing, MI 48823, USA

P. Yanda

Institute of Resources Assessment, University of Dar Es Salaam, PO Box 35097,

Dar Es Salaam, Tanzania

N. Moore $(\varangle)$

Department of Geography, Michigan State University, 202 Manly Miles Bldg,

East Lansing, MI 48823, USA

e-mail:moorena@msu.edu 
Crop yields were estimated with a process-based simulation model. The results suggest that: (1) GHG-influenced and LCLUC-influenced yield changes are highly heterogeneous across this region; (2) LCLUC effects are significant drivers of yield change; and (3) high spatial variability in yield is indicated for several key agricultural sub-regions of East Africa. Food production risk when considered at the household scale is largely dependent on the occurrence of extremes, so mean yield in some cases may be an incomplete predictor of risk. The broad range of projected crop yields reflects enormous variability in key parameters that underlie regional food security; hence, donor institutions' strategies and investments might benefit from considering the spatial distribution around mean impacts for a given region. Ultimately, global assessments of food security risk would benefit from including regional and local assessments of climate impacts on food production. This may be less of a consideration in other regions. This study supports the concept that LCLUC is a first-order factor in assessing food production risk.

\section{Introduction}

Assessing food production variability - a key element in food security risk-for developing nations is vital for policymakers, natural resource managers and nongovernment organizations (Parry 1990; Parry et al. 2004). Changes in climate due to enhanced greenhouse gases (GHG) are expected to have widespread impacts on food production in many regions (Lobell et al. 2008; Burke et al. 2009); indeed, GHG-driven climate change in East African region is likely underway now (Boko et al. 2007) impacting the livelihoods of millions of people. Climatic responses associated with increasing concentrations of GHG in East Africa are complex (Neilson and Drapek 1998) yet are generally expected to nudge the region towards a warmer and wetter state (Hulme et al. 2001).

Considerable research has recently focused on the potential impacts of climate change on food production (Parry et al. 1999; Livermore et al. 2003; Funk et al. 2005; Rosegrant et al. 2005; Tiffin and Xavier 2006; Thornton et al. 2009, among others). To date, many of these studies have been global in scope, often conducted using (1) empirical, linear models (e.g., Lobell and Field 2007) relating food production and climate variability and (2) input from climate models at coarse scales, usually from General Circulation Models (GCMs) either directly, downscaled, or aggregated (Lobell et al. 2008; Funk et al. 2008).

However, as many of these researchers have suggested, these approaches have several limitations. First, the scale and heterogeneity of climate impacts on food production may not adequately capture variability that is important in locations where technological capabilities and adaptations are limited and crops are grown for local subsistence. It is well known that GCMs (typically run at grid spacings of $\sim 120 \mathrm{~km}$ or coarser) cannot simulate atmospheric dynamics associated with landscape variability. Second, impacts due to changes in land use and land cover are generally not explored. Third, atmospheric impacts caused by land cover and land use change (LCLUC) in parallel with changing greenhouse gas concentrations could also affect crop yields.

Recent efforts to prioritize climate change adaptations from the food security perspective are needed (e.g. Funk et al. 2008; Lobell et al. 2008) but lack important 
contributions from regional landscape heterogeneity that impact crop yields as they are assessed at fine resolutions. These complexities are evident in the strongly contrasting conclusions about East African food security as reported by Lobell et al. (2008) — who find East Africa insulated from increased risk-and Funk et al. (2008), who find "dangerous increases" Eastern and Southern Africa's food security risk. Thornton et al. (2009) argue strongly against using large spatially contiguous domains, such as those at national scales, to examine adaptations in regions with large variations in topography and average temperature.

Several physical features also contribute to East Africa's high local variability in climate: highly variable topography ranging from sea level along the coasts and the African Rift Valley to large continental volcanoes, expansive inland lakes (Anyah et al. 2006), complex seasonality associated with Indian Ocean influences (Black et al. 2003; Black 2005; Anyah and Semazzi 2007) and complex equatorial circulations (Ogallo 1989; Mutai and Ward 2000; Camberlin and Philippon 2002) that create conditions favorable for double cropping near the equator and single cropping at the northern and southern extents of the region. In this study we integrate fine resolution, spatially explicit crop-climate-land use models that incorporate the complex spatial heterogeneity of East African systems so that we can explore future climate change effects due to GHG and LCLUC on food production risk.

A second limitation of climate-food production studies conducted to date is that GCM-statistical climate-food production models miss important feedbacks that may result in systems where land use/cover change may alter local and/or regional climate dynamics. Several studies have demonstrated that Land Cover and Land Use Change (LCLUC) alter surface albedo which in turn may influence local and regional climate dynamics (Charney et al. 1977; Lofgren 1995; Semazzi and Song 2001). Thus LCLUC can exert an important influence on regional climate (Pielke et al. 2007; Anyah et al. 2006) and even the vegetation response to rainfall (Serneels et al. 2007), possibly with positive or negative feedback patterns. Besides GHG, LCLUC is also a primary driver of climate change at local to-in some cases-much larger scales (Feddema et al. 2005; Pielke et al. 2002; Maynard and Royer 2004). Land historically used for animal grazing in East Africa is being converted to cropland, and urban areas are expanding dramatically. These trends are expected to continue in the future (Olson et al. 2004; Mundia and Aniya 2005; Olson et al. 2007). Thus, LCLUC effects may moderate or amplify the GHG effects on climate change ( $\mathrm{Li}$ and Mölders 2008). Anthropogenic effects include LCLUC.

Finally, crop yields are a function of many different biophysical factors (cf. Boyer 1982; Boote and Sinclair 2006; Hay and Porter 2006) including temperature, rainfall, length of season, and nutrient availability, among others. The interaction of these variables is known to be complex and likely nonlinear, and, as such, may not be well explained by linear statistical models. Relying on process-based models instead may help to better understand how complex climate patterns in addition to nutrient limitations may impact livelihoods of people in developing countries limited by technological solutions. Although pests, diseases and natural hazards are absent in most crop models, and there are concerns about reliability (Boote et al. 1996), crop models have been shown to be useful in understanding climate-crop interactions in many regions, including East Africa (e.g. Thornton et al. 2009).

Here, we attempt to address the shortcomings of coarse spatial resolution assessments of the impact of climate change on food security through high resolution 
studies of climate change, coupled to a process-based crop simulation model. Our hypothesis is that land use/cover change feedbacks may alter an assessment of future food production resulting singularly from GHG-induced climate change alone. In addition, we test whether or not finer and coarse resolution evaluations strongly differ. The work presented here is part of a larger project, the Climate-Land Interaction Project (Olson et al. 2007), aimed in part at understanding the relative variability and sensitivities of regional climate, crop yield, and human systems due to GHG forcings and LCLUC each of which operate in very different but important ways. Our objectives are threefold:

I. To test if spatially homogenous forcings (e.g. GHG forcings that show warming everywhere) can result in complex, heterogeneous crop responses as a result of spatial and temporal landscape heterogeneity.

II. To test whether spatial and temporal changes in temperature and precipitation due to LCLUC produce yield changes similar to GHG effects.

III. To examine how a process-based, high-resolution modeling approach differs from a coarse resolution statistical approach for estimating the impacts of climate change on food production risk.

\section{Models and methods}

This study focused on the East African countries of Kenya, Uganda, Tanzania, Burundi, and Rwanda (Fig. 1). This domain spans dramatic changes in elevation, annual rainfall, land cover, and soil type. As such, it is an appropriate location for examining the effects of landscape heterogeneity on climate variables and crop yield. Figure 1a shows average annual rainfall from the Worldclim data set (Hijmans et al. 2005), with population distributions (Fig. 1b) following a similar spatial distribution. Figure 1c is an estimate of maximum potential agricultural extent for maize that shows high fragmentation and heterogeneity. In contrast, projected changes in annual rainfall from the National Center for Atmospheric Research's Community Climate System Model (CCSM) 4.0 Scenario A1B from 2000-2009 to 2050-2059 (Fig. 1d) suggest a wetter trend but do not reflect complex local and mesoscale atmospheric features. The framework for examining the role of regional landscape heterogeneity on crop yields required inputs of land cover change and climate change as illustrated in Fig. 2. The elements of each model segment are described in more detail below.

\subsection{Land cover/land use change modeling}

We developed a hybrid land-use and land cover classification scheme (Torbick et al. 2006), in part, from Africover (2002) and with input from local African experts. Workshops of experts were used as one of the sources of information on future changes in land use; the basis for such future predictions was developed from a number of anticipated development programs, strategies, and other factors ranging from national to local scales. Landscapes for agriculture and urban were projected to 2050 using the artificial neural network and GIS based Land Transformation Model (Pijanowski et al. 2002, 2005, 2009) using regional data on roads, elevation, soils, rainfall, surface water and existing urban boundaries. Population data from the UN (2007) were used to scale the amount of required rainfed agriculture to 2050. The 

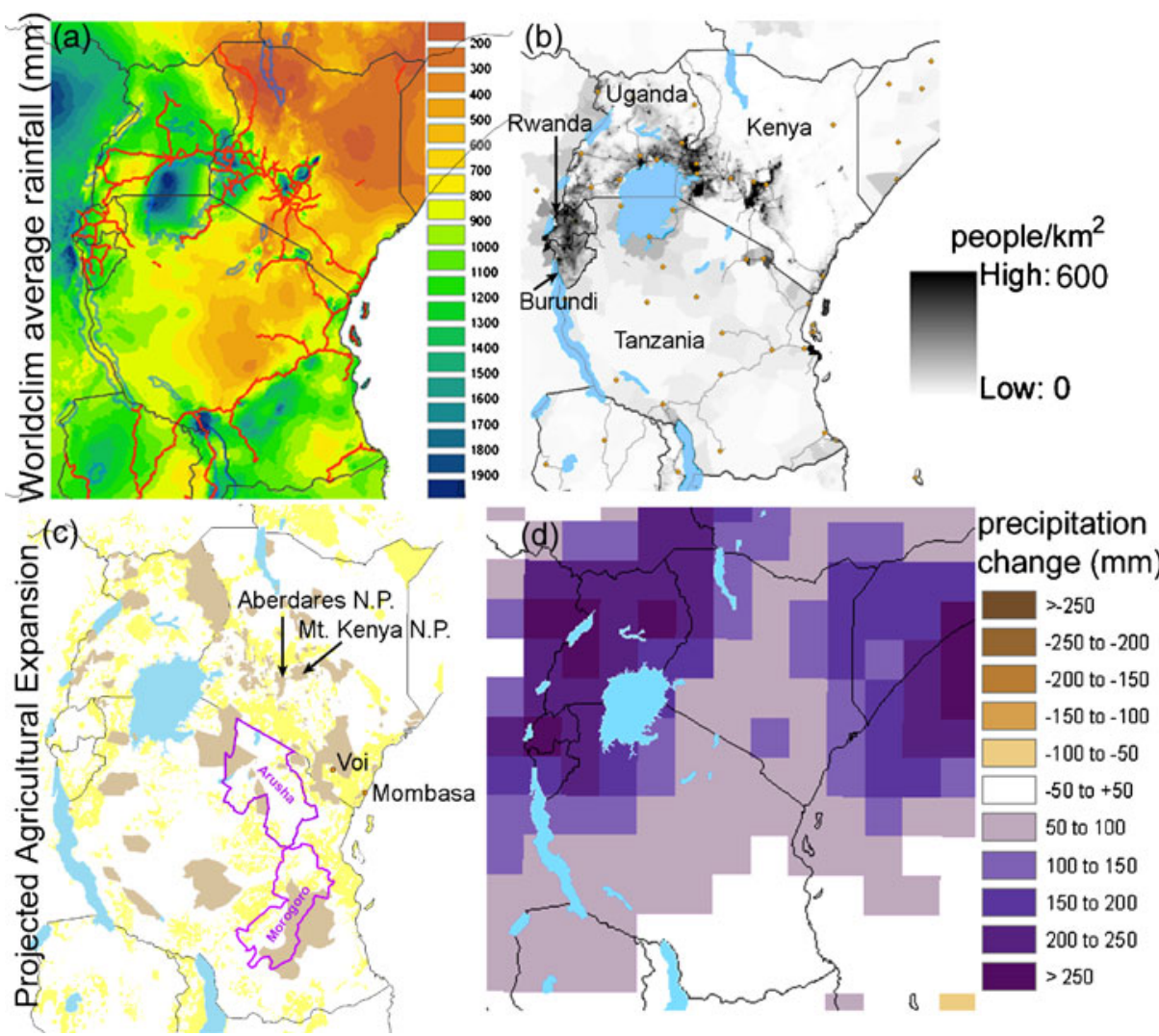

Fig. 1 Key spatial aspects in simulating current and future variability of food production in East Africa. a Average annual rainfall from Worldclim; b Population density from CIESIN (Center for International Earth Science Information Network); c LCLUC projection of agricultural expansion from 2000-2050 (yellow) and national parks (brown); d climate change projection of CCSM mean annual precipitation from 2000-2050 under the SRES A1B scenario

model was developed at $1 \times 1 \mathrm{~km}$ resolution. Overall, we projected that East Africa would experience more than a doubling of total cropland by the year 2050. This is an extreme case, pursued to elicit a strong signal/noise ratio for understanding the scale of land change effects, and is not a likely outcome. This cropland expansion resulted in a decrease in broadleaf forests, open and closed savanna, shrublands and grassland. These were needed because of East Africa's bimodal phenology

Fig. 2 Flow diagram linking the land cover model, climate model, and crop model

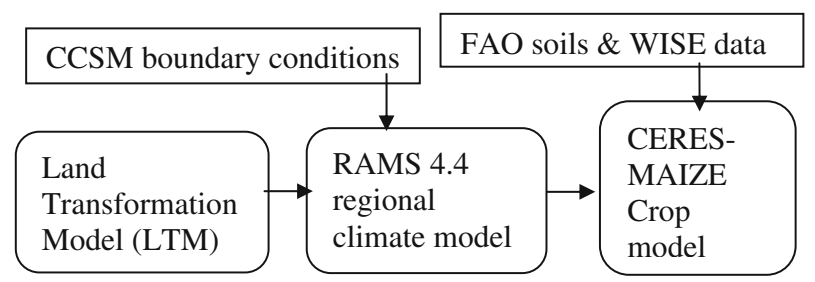


for crops and other seasonal greening landscapes associated with "long rains" and "short rains" precipitation. We did not investigate subvarieties of LCLUC such as afforestation, pasture expansion, or silviculture. Increased agricultural expansion in some places (e.g. southern Kenya/Tsavo) is not realistic but is a consequence of extreme agricultural expansion; some small concessions like these were deemed acceptable for the purposes of a sensitivity experiment.

\subsection{Regional atmospheric modeling}

We used the Regional Atmospheric Modeling System (RAMS version 4.4; Cotton et al. 2003), a state-of-the-art limited-area atmospheric model. Our domain, $84 \times 76$ grid points, covered Kenya, Tanzania, Uganda, and several neighboring countries at a $36 \mathrm{~km}$ horizontal grid spacing and a vertical domain (32 levels) stretched to $32581 \mathrm{~m}$ above mean sea level, with the lowest level thickness $100 \mathrm{~m}$. We employed the Kain-Fritsch convective parameterization (Kain and Fritsch 1993). Surface and vegetation dynamics were governed by the LEAF-2 sub-model (Walko et al. 2000), and land cover parameters like albedo, fractional cover, etc were linked to appropriate Global Land Classification (GLC) classes. Annual $\mathrm{CO}_{2}$ concentrations and 6-hourly atmospheric boundary conditions for current and future climate were from the CCSM 3.0 model (Scenario A1B) for the decades 2000-2009 and 2050-2059 (Collins et al. 2006). The increased rainfall over this time span in CCSM's average annual precipitation is shown in Fig. 1d. We explored climate impacts attributable solely to GHG changes and to LCLUC. RAMS was thoroughly tested and evaluated with recent observed data using NCEP forcings. Regionally specific fractional cover and leaf area index (LAI) estimates developed from MODIS imagery (Wang and Yang 2007) were incorporated to improve the regional atmospheric model's performance (Moore et al. 2009). Since Indian Ocean temperatures may strongly influence coastal crop production (Funk et al. 2008), we included monthly CCSM sea surface temperatures from the same scenario into RAMS and included a sizeable portion of the Indian Ocean in our domain.

\subsection{Crop yield modeling}

To estimate the growth, development, and yield of crops under future and current climate and landscape conditions, we used a deterministic, process-based simulation model for maize. We used maize as a representative proxy food crop for the region. We used the CERES-Maize crop model (Ritchie et al. 1998) as currently implemented in version 4 of the Decision Support System for Agrotechnology Transfer (DSSAT; ICASA 2007) for all crop simulations. CERES-Maize requires daily precipitation, maximum and minimum temperatures, and incident solar radiation data. Daily time series of these were generated with MARKSIM (a statistical weather generator of daily data from monthly data; c.f. Jones and Thornton 2000) variables for historical and projected future time frames. We produced monthly mean data from RAMS outputs for the four decadal simulations in this study following the methods described by Jones and Thornton (2003). Soils data were derived from Food and Agricultural Organization soils map of world (FAO 1995) converted to a 30 arcsecond grid which identifies all agriculturally suitable soils based on FAO soil unit ratings (FAO 1978) in the study region. We then used representative soils profiles 
from the International Soils Reference and Information Center's World Inventory of Soil Emission Potential Data base (Batjes and Bridges 1994) as modified by Gijsman et al. (2007) for each of the $18 \mathrm{~km}$ pixels in the domain where maize yield would be simulated. We assumed current representative smallholder cultural practices for maize cultivation; planting was assumed to occur automatically once the soil profile has received a thorough wetting at the start of the rainy seasons, and the crop was planted at a typical density of 3.7 plants $/ \mathrm{m}^{2}$. A nominal amount $(5 \mathrm{~kg} / \mathrm{ha})$ of inorganic $\mathrm{N}$ was applied to the crop at planting. CERES-Maize does not account for the effects of pests, diseases and natural calamities such as hail. In this experiment, maize production was simulated in major production areas of other crops (e.g. rice, wheat, millet) as a proxy for productivity in general to assess yield sensitivity since maize is the primary food crop in East Africa. Although our results have this inherent inaccuracy of one-crop modeling and other crops may respond in different ways (c.f. Thornton et al. 2008), this method still allows for testing whether or not regional heterogeneity in GHG and LCLUC forcings has the potential to significantly affect crop production. As responsiveness of $\mathrm{C} 4$ crop yield to doubling of $\mathrm{CO} 2$ from 350 to $700 \mathrm{PPM}$ was in the range of $4.2 \%$ increase under adequate soil moisture as summarized by Boote et al. (2010). In view of this marginal yield increase in C4 crops under adequate soil moisture due to $\mathrm{CO} 2$, we did not consider it in our simulation studies.

For comparing climate change effects on maize yield using a coarse resolution approach, we followed the technique of Lobell et al. (2008), as detailed in their supplemental online material. To briefly summarize that technique, we derived trends using the first-differences method (where year-to-year changes in modeled data are added to baseline observed data) from the same CCSM data used in our regional modeling to project climate (temperature and precipitation) to 2050 . We also used the first-difference method for FAO yield data for Kenya, Tanzania, Rwanda, Burundi, and Uganda. FAO first-difference yield trends by country were then aggregated for 2050. In cases where actual values were needed instead of differences, we used CCSM changes superimposed on Worldclim climatology to tether the data to the real world. The point of the exercise was to test if finer time scales and spatial scales would give a significantly different average result in food yield, or if the yields would tend to be relatively insensitive to the scales of the models.

\subsection{Experimental design}

To evaluate the relative effects of GHG and LCLUC changes at fine resolution, we constructed four decade-long numerical land-climate simulation experiments:

Case 1 current GHG (CCSM 2000-2009), current land cover; "baseline simulation" Case 2 elevated GHG (CCSM 2050-2059), current land cover

Case 3 current GHG (CCSM 2000-2009), expanded land cover

Case 4 elevated GHG (CCSM 2050-2059), expanded land cover

Case 1 provides a baseline for comparison under current $\mathrm{CO}_{2}$ levels using ClipCover as the land surface. The two sensitivity experiments tested GHG impacts on yield for future (2050-2059) climate dynamics under elevated $\mathrm{CO}_{2}$ levels (Case 2), LCLUC impacts on yield under current $\mathrm{CO}_{2}$ levels (Case 3) and future LCLUC and GHG 
Table 1 Local characteristics and yield influencing factors in selected SOIs

\begin{tabular}{|c|c|c|}
\hline SOI exhibiting an effect & Characteristic of SOI & Yield influencing factor \\
\hline SOI 1: Burundi & High elevation & Low Tmax \\
\hline SOI 2: Western Tabora & High elevation & Low Tmax \\
\hline SOI 3: SE Lake Victoria & Near Lake & Low rainfall \\
\hline SOI 4: Morogoro & Sandy soils & Nitrogen stress \\
\hline SOI 5: Central Uganda & High elevation $(\sim 1200 \mathrm{~m})$ & High Tmax \\
\hline SOI 6: Kenya highlands & High elevation & Low Tmax \\
\hline SOI 7: Longido/Nairobi & High elevation & Low Tmax \\
\hline SOI 8: Kilimanjaro & High elevation & Low rainfall \\
\hline SOI 9: Voi/Mombasa & Low elevation & Low rainfall \\
\hline SOI 10: Lamu coast & Low elevation & High Tmax \\
\hline SOI 11: Rwanda & High elevation & Cool; long CGD \\
\hline SOI 12: South Uganda & Near lake & Cloudy \\
\hline SOI 13: Central Uganda & High elevation & Low rainfall \\
\hline SOI 14: S. Lake Victoria & Near lake & Cloudy \\
\hline SOI 15: Pangani & High elevation & Short CGD \\
\hline SOI 16: East Mt Kenya & High elevation & Low rainfall \\
\hline SOI 17: Lamu Coast & Near water body & Hot; low rainfall \\
\hline SOI 18: Iringa & High elevation & Short CGD \\
\hline SOI 19: Morogoro & Sandy soils & High rainfall \\
\hline SOI 20: Dar Es Salaam & Near water body & Low rainfall \\
\hline
\end{tabular}

High elevation is defined as $>1,000 \mathrm{~m}$; low elevation as $<1,000 \mathrm{~m}$; increased temperatures cause a decrease in growing season length, which can either increase yield (if currently cool) or decrease yield (if currently warm)

combined (Case 4). Daily minimum temperature (Tmin), maximum temperature (Tmax), and precipitation were input to the CERES-maize model. From these simulations were calculated changes in yield, as well as additional variables like crop growth duration (CGD), water stress and nitrogen stress. CGD is the length of time (days) between planting and physiological maturity. Differences in yield due to GHG effects (Case 2-Case 1) can be compared to estimates using a linear regression model to determine if coarse-resolution results are similar to fine-resolution results. Differences in yield due to LCLUC effects (Case 3-Case 1) will illustrate the possible magnitude of land change effects on climate. We hypothesize that land change effects have yield impacts of similar magnitude to GHG effects and ought to be included in assessments of food production risk. Regional models are suitable tools to identify areas of high sensitivity to GHG change and LCLUC. Since food security risk is influenced by extreme climate factors, we also selected 20 SOIs (Subregions Of Interest) displaying large changes in yield from each experiment to explore further for this experiment; Table 1 lists these SOIs and salient characteristics.

\section{Results}

In order to demonstrate the utility of an explicit spatial high-resolution analysis of climate change on maize yield, we illustrate yield changes associated with GHG and LCLUC in 20 selected SOIs, 10 SOIs for each climate forcing. These SOIs are the numbered colored polygons in Figs. 3 and 4 with SOI color indicating the main variable responsible for the change in annual yield. The SOIs were chosen to show 

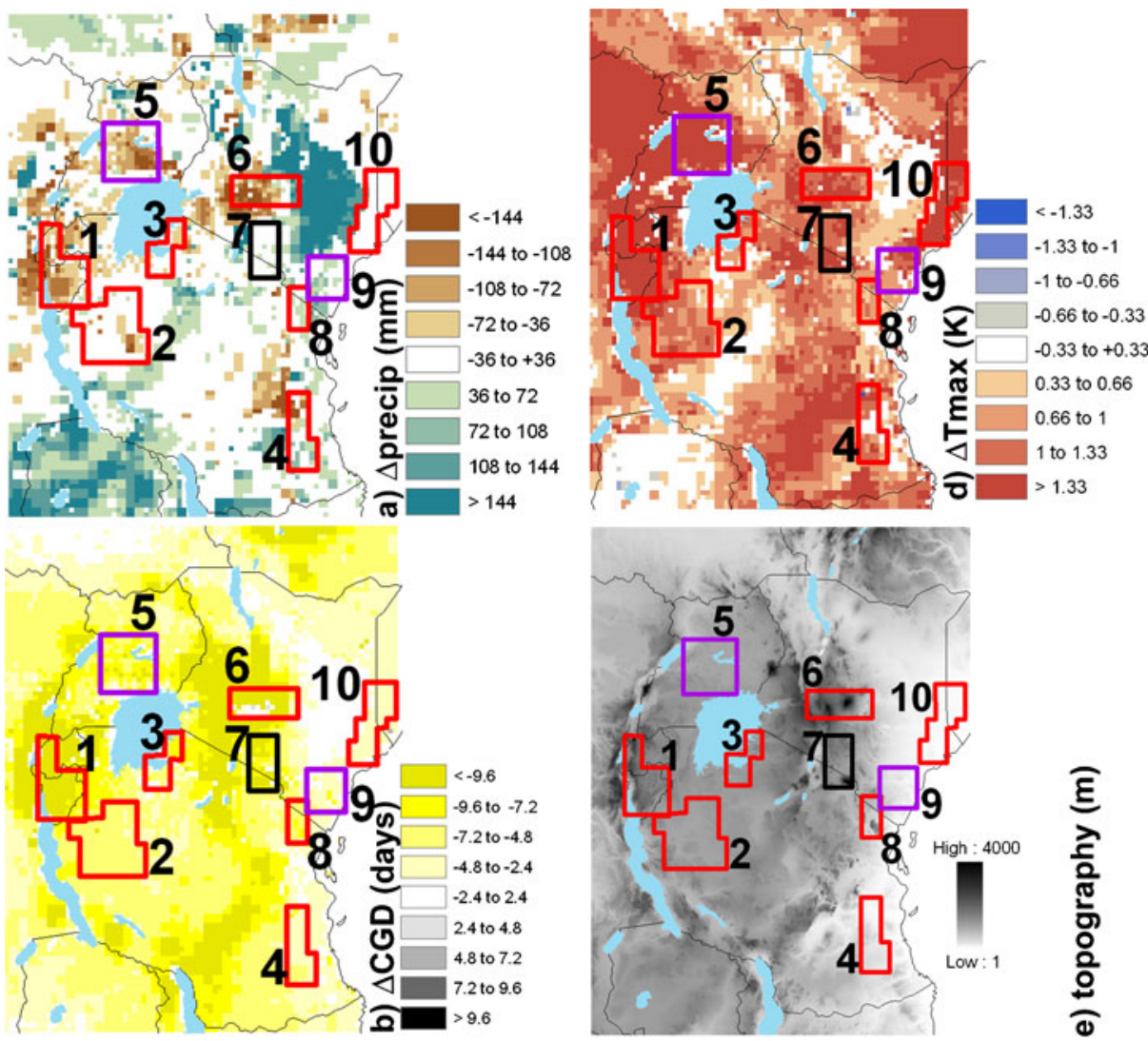

틀
등
흥
응
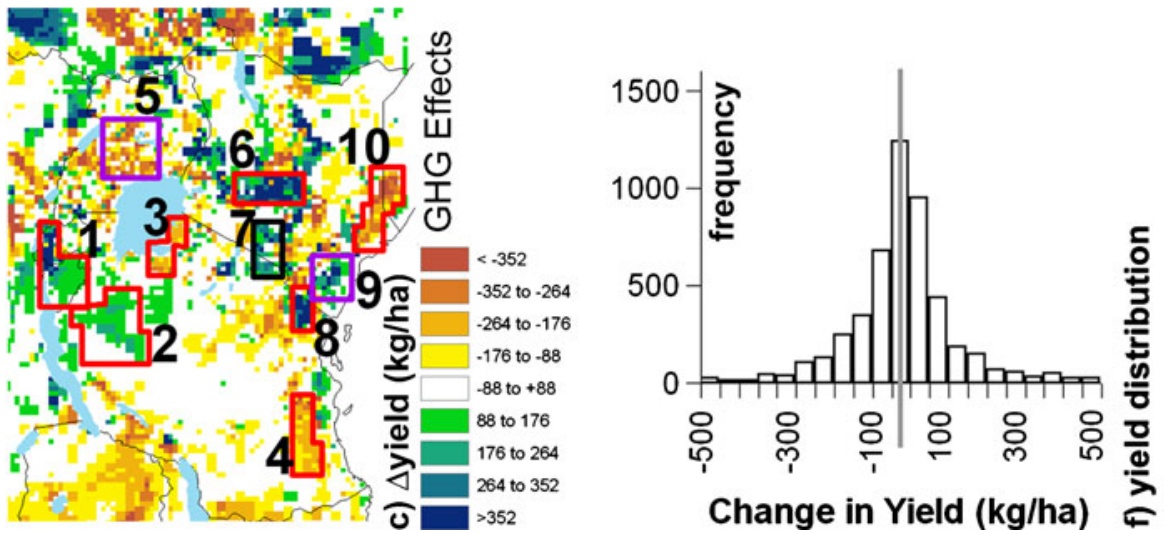

Fig. 3 GHG effects: average growing-season differences between 2000-2009 and 2050-2059 in: a mean precipitation, b crop growth duration (CGD), $\mathbf{c}$ yield change for the study area, d average maximum temperature, e topography, and $\mathbf{f}$ a histogram of yield change distribution for the 5 nations. Increments shown on a through $\mathbf{d}$ are half of one standard deviation $(\mathrm{s} / 2)$ for each scale. Numbered Subregions Of Interest (SOIs) selected for high yield sensitivity are shown with colors indicating the driving climate factors behind the yield changes: red warmer, blue cooler, purple change in temperature and rainfall, black complex factors 

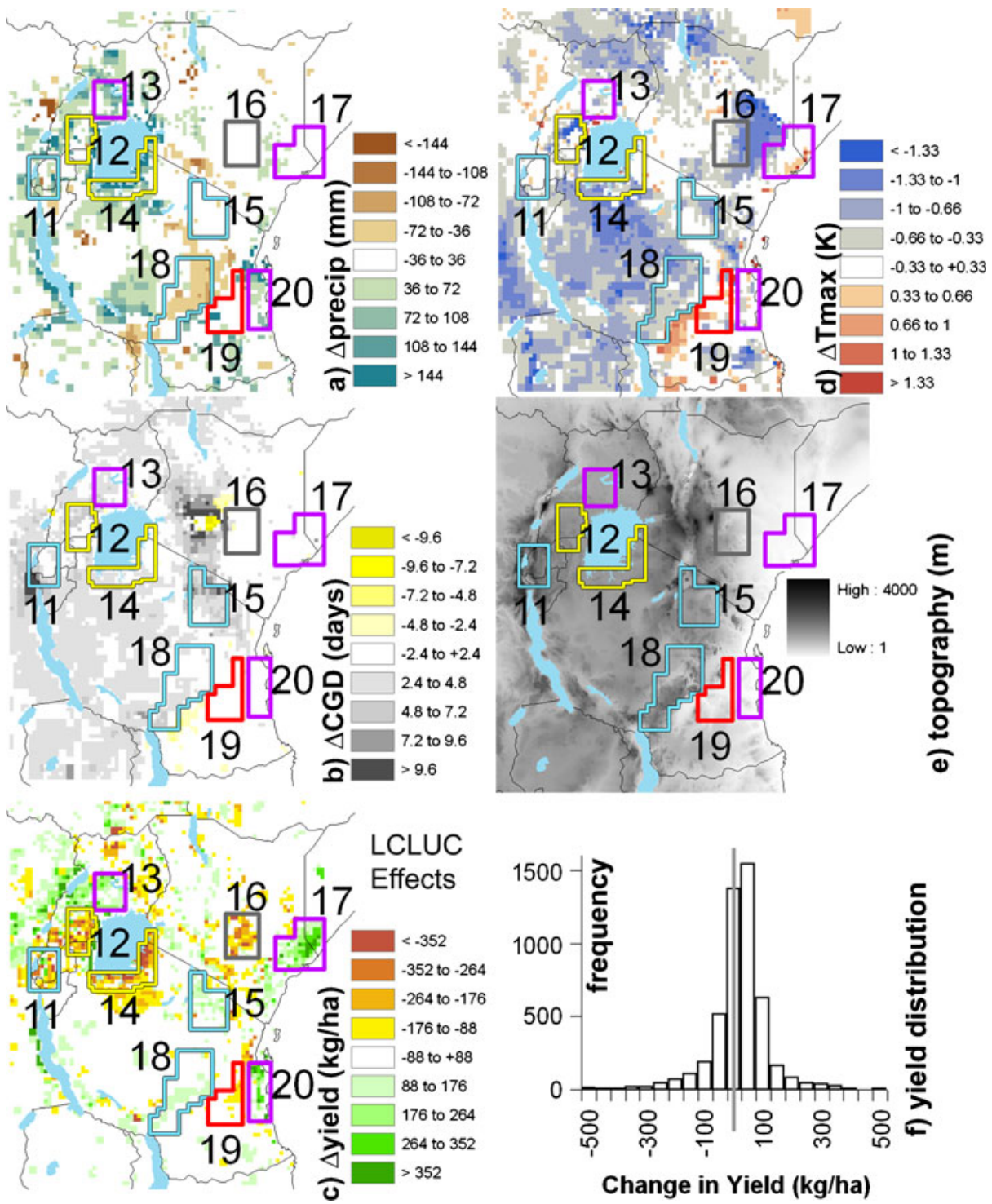

Fig. 4 LCLUC effects: average growing-season differences in: a mean precipitation, $\mathbf{b}$ CGD, $\mathbf{c}$ yield change for the study area, $\mathbf{d}$ average maximum temperature, $\mathbf{e}$ topography, and $\mathbf{f}$ histogram of yield change distribution for the 5 nations. Numbered Subregions Of Interest (SOIs) selected for high yield sensitivity are shown with colors indicating the driving climate factors behind the yield changes: red warmer, blue cooler, yellow decreased solar radiation, purple increased rainfall, grey complex factors

which yield changes that are sensitive to a variety of conditions of a regional nature. The overarching theme relating these 20 regions is heterogeneous yield response to spatially homogeneous/spatially uniform forcings caused by GHG or heterogeneous LCLUC forcings. That is, yield responses are strongly governed by regional and 
local features. Many of the selected areas are close to one another, yet they are associated with different yields, different climate forcings, or both. The color of the SOIs was assigned only if the change in the indicated climate variable changed more than the 10-year standard deviation. Thus, these yield-climate changes are not simply correlated, but infer causation.

\subsection{Overview of spatial impacts of elevated GHG effects (Case 2)}

Figure 3 shows changes in (a) growing season precipitation (PCP), (b) crop growth duration (CGD), (c) yield, and (d) average growing season Tmax between 2000 and 2050 under elevated GHG conditions using current land cover inputs (i.e., Case 2). These variables were selected to illustrate their main influences on maize yield. Topography in the study area is shown for reference in Fig. 3e. The PCP, Tmax and CGD exhibit a very strong correlation with elevation. Under elevated GHG, the East African highlands warm dramatically, accelerated crop development leading to decrease in CGD. Warming in other areas (e.g. Morogoro in SE Tanzania) was associated with smaller but important decreases in CGD, particularly in loweraltitude areas that are already warm. However, PCP and CGD in Fig. 3 are associated with complex and heterogeneous yield responses. Changes in PCP, Tmax, and CGD do not translate to direct and obvious changes in yield; rather, the yield changes show strong heterogeneity due to complex ways on the influence of driving variables.

Singly, PCP and CGD can affect yields significantly but together, their changes lead to heterogeneous responses in yield which is not easily deduced from broad features-for example, changes in PCP along with temperature change (influencing CGD) drive both increases (i.e. around Voi/Mombasa) and decreases (i.e. in central Uganda) in yield. In this example, increased precipitation near Voi/Mombasa alleviated water stress, thereby increasing simulated maize yields; however, in central Uganda a modest decrease in growing season precipitation together with elevated nighttime temperatures (which shorten the growing period) lead to a dramatic decline in yield; with an already short growing period, any water stress combined with a shortening of the growing period can rapidly shrink crucial phases of maize development. Similarly, increasing temperatures can also cause both yield declines as well as yield increases. Although warmer temperatures tend to contract the growing season-causing yield declines in hot regions (for example, Central Uganda)warmer temperatures in the highland areas actually increase yields by improving plant function especially during the grain-filling phase (for example, the Aberdares and Mt. Kenya). Results shown in Fig. 3 indicate that complex yield changes are associated with spatially uniform/homogeneous climate drivers. The average yield is only part of the story; several locations show dramatic changes in yield. For example, the histogram in Fig. 3f shows a broad distribution of changes in yield occurring across the entire East African area plotted from values in 3(c) with a standard deviation of $176 \mathrm{~kg} / \mathrm{ha}$ (this is given as an indication of domain-scale variability) which will be masked if only average yield is considered.

\subsection{Overview of spatial impacts of LCLUC effects (Case 3)}

Figure 4 shows changes between 2000 land cover and 2050 land cover in (a) PCP, (b) CGD, (c) yield, and (d) Tmax under LCLUC due to expansion of agriculture 
into existing savanna conditions (i.e., Case 3). Simulated LCLUC in savannah areas replaces moderate albedo grasses in the future that translate into higher albedo bare soil for part of the maize growing season, and similar albedo maize later in the growing season. This higher albedo under agricultural expansion leads to lower absorption of shortwave radiation that leads to slightly cooler maximum temperature as evident in Fig. 4d. These cooler maximum temperatures increase the growing season and CGD. Topography is again shown in 4(e) for reference. Figure 4f shows the distribution of yield change from 4(c; The gray vertical line is zero). The LCLUC effects, on average, produced yield changes at a magnitude similar to those of GHG effects (compare to Fig. 3c; see also Fig. 5d), but the climate changes associated with LCLUC are more disaggregated and concentrated than GHG effects. The GHG effects dominate extremes in yield change.

Although more obvious, these results show that heterogeneous changes in land cover can cause heterogeneous maize yield changes. For example, SOI 15 and SOI 16 in Fig. 4 were both areas of cooler Tmax with time but had opposite responses in yield change. A strong relationship with topography-both with elevation and proximity to water bodies - is evident with the climate variables, although PCP changes are more muted and influenced by proximity to water bodies (leading to increased rainfall) or in steppe areas like Arusha in SOI 15 (decreased rainfall). Similarly, CGD increases are closely linked to the highland areas but show more muted responses elsewhere. Processed-based modeling is capable of capturing these relationships. As a second example, the opposite yields in SOI 12 and SOI 13 are driven by differences in solar radiation and rainfall despite both areas receiving similar increases in rainfall. Again, the changes in yield respond differently in different areas despite a similar climate forcing. The model results in Fig. 4c show that in some cases, large and broad climate perturbations (e.g. Western Tanzania) led to no significant changes in yield. Often, the model shows rainfall changes being driven by changes in convection, which has been observed elsewhere (e.g. Allard and Carleton 2010).

\subsection{Overview of combined GHG and LCLUC effects}

GHG effects on climate dwarf LCLUC effects across much of the domain, and that dominance extends to average yields in Case 4. Figure $5 \mathrm{a}-\mathrm{c}$ shows the yield changes due to individual and combined effects, given here in percentage terms. Individual climate factors for Case 4 (not shown) are quite similar to Case 2 climate factors shown in Fig. 3. Although the LCLUC effects on climate and yield are generally smaller, they are not negligible. These areas are all important agricultural areas, and yield changes there may have a large impact on food security. Although GHG effects are clearly larger than LCLUC effects, LCLUC effects are not second-order or negligible. Figure $5 \mathrm{~d}$ shows the ratio of yield changes (ratio $=\mathrm{LCLUC} / \mathrm{GHG}$ ) to illustrate where LCLUC causes a similar or larger impact on yields than GHG; a ratio of one would indicate that LCLUC and GHG have an equal impact on change in yield. Areas with marginal yields for Case 1 were omitted from the ratio, as were small values for GHG effects to avoid curiously small denominators. Both green and yellow represent areas where LCLUC impacts are larger than GHG impacts (i.e. $\mid$ ratio $\mid>1$ ). Green is used for increased yield in an LCLUC-dominated area; yellow is used for decreased yield in an LCLUC-dominated area. Grey represents areas where LCLUC impacts are less than GHG effects (i.e. |ratio $\mid<1$ ). For 
Fig. 5 Percentage change in maize yield compared to the baseline simulation (Case 1) for: a GHG effects/Case 2, b LCLUC effects/Case 3, and $\mathbf{c}$ Combined effects/Case 4. d Yield change of Case 4-Case 2, which shows the role of LCLUC in perturbing $\mathrm{GHG}$ effects

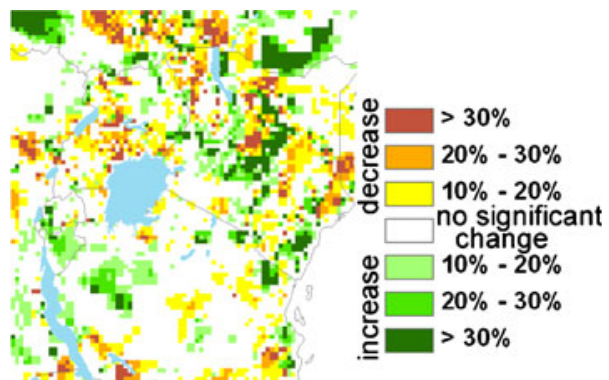

(a) GHG Effects

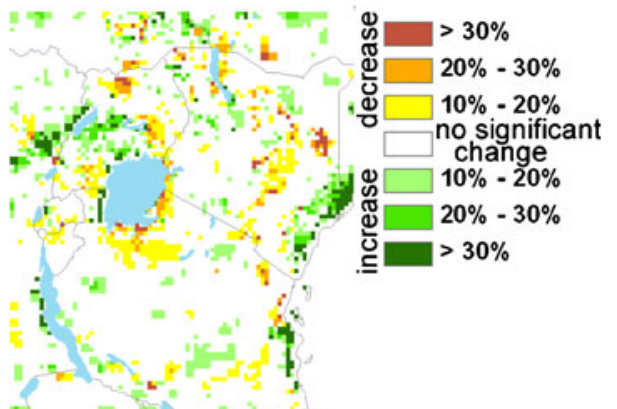

(b) LCLUC Effects

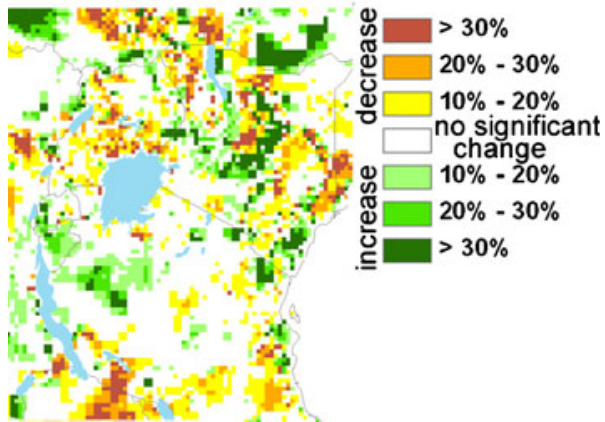

(c) Combined Effects

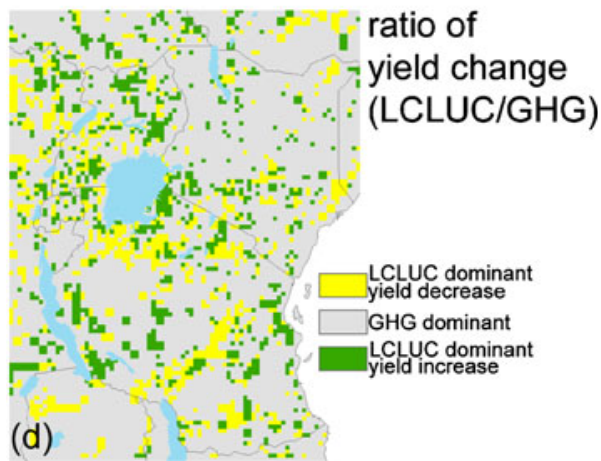


Fig. 5d, approximately $30 \%$ of the domain is not dominated by GHG effects alone; this demonstrates that LCLUC factors are of first-order consideration for food production.

a
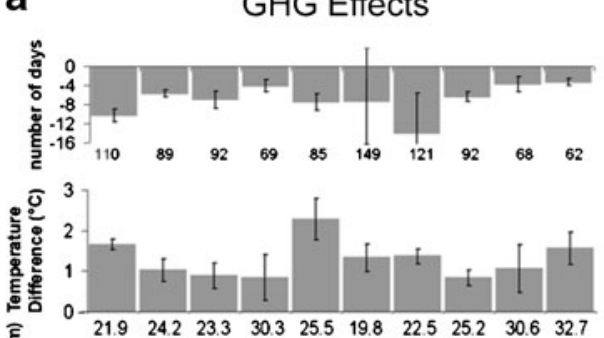

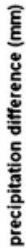
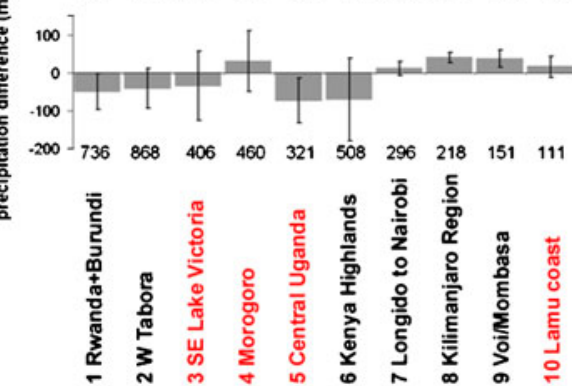

black=region of increased yield
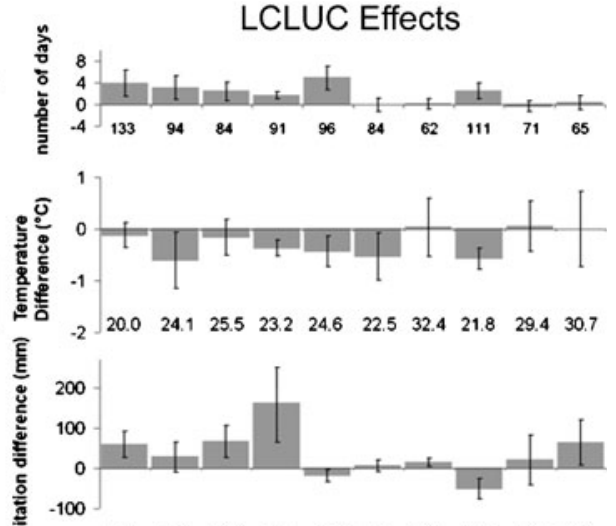

$\begin{array}{llllllllll}845 & 487 & 332 & 444 & 447 & 341 & 101 & 489 & 627 & 222\end{array}$

red=region of decreased yield

b

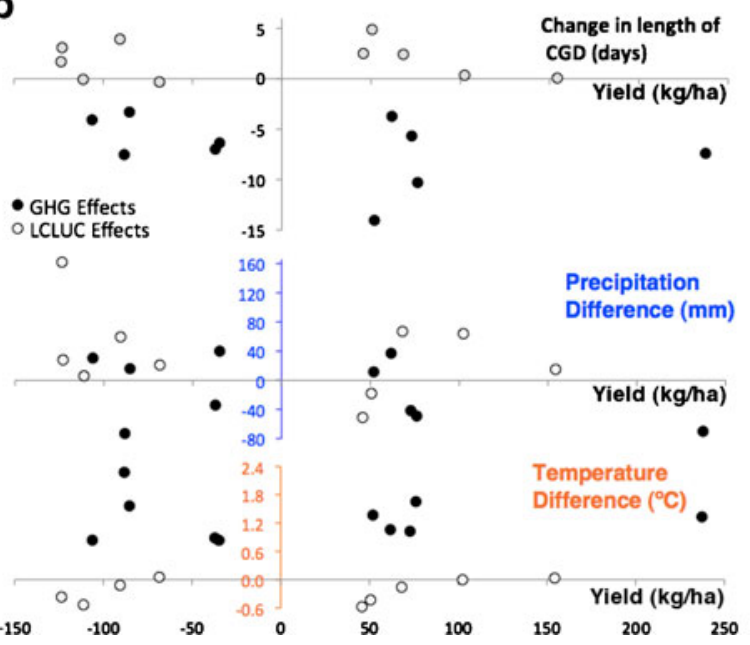

Fig. 6 a Changes in selected climate variables for the 10 GHG regions (left) and the 10 LCLUC regions (right) outlined in Figs. 3 and 4. Values along the bottom of each graph give average values from the baseline simulations to help understand the importance of the change. Red decreasing yield SOI, black increasing yield SOI. Each region has at least 30 pixels. b The same data re-plotted to show the lack of correlation between the individual climate forcings and the simulated yields 
3.4 Complex drivers of yield change

Many different yield changes occur despite similar climate forcings, as shown in Fig. 6a. For example, PCP in much of the highland areas decreases, leading to regions of both increased and decreased yield. This is illustrated in Fig. 6a, left panel, where SOIs 2, 5, and 6 all show decreased precipitation, though SOI 5 has a yield decrease and SOIs 2 and 6 show yield increases. These contrary results occur because of other factors-such as temperature increases in the case of Central Uganda. Similarly, at lower elevations, central-eastern Kenya (semi-arid SOI 16) and SW Tanzania (extremely rainy near the Zambia border, not an SOI) show opposite responses in yield despite enhanced rainfall in both locations. Changes in Tmax and CGD are very strongly correlated, but these are both shown because in some cases Tmax may change significantly while CGD does not (e.g. SOI 16) or vice versa (SOIs 11 and 13).

In some instances, seemingly contrary results (e.g. SOI 8: less rainfall, but a yield increase) occur for the same selected regions. This occurs when averages over the growing season do not reflect daily differences in rainfall intensity, cloudiness, or other factors. For our first example, under LCLUC effects, Southern and Central Uganda (Fig. 6a, SOIs 12 and 13) both receive increased rainfall and are near one another. However, the yield changes are opposite in sign, and the increased yield in Central Uganda is due to additional rainfall while the decline in yield to the south is due to decreased temperature and decreased solar radiation (not shown). Under GHG effects, our second example, a similar counterintuitive response is also evident for GHG in SOIs 9 and 10 which both undergo large increases in Tmax. SOI 9 receives a small amount more rainfall (and at timely intervals during the growing season, while SOI 10 receives no significant additional rainfall, thus reaching high levels of water stress and high temperatures stress. Curiously, a large increase in rainfall between SOIs 6 and 10 (Fig. 6 shows a large decrease in PCP in SOI 6 and no change in SOI 10) leads to different yield changes - an increase in higher altitudes, a mild decrease in lower altitudes (see SOI 10 in Fig. 4a-already marginal), and no change in others. This reiterates that even modest simulations of food production can display a variety of counterintuitive outcomes that depend sensitively on local and regional conditions.

Figure $6 \mathrm{~b}$ is a further illustration that these variables show very low correlation at regional scales. The horizontal axis is the same for all three panels. Although distinct differences are evident between GHG and LCLUC effects, their relative forcings show no evident pattern.

\subsection{Coarse-resolution versus fine-resolution approach/assessment}

One of objectives in this study was to compare a coarse-resolution assessment to a fine-resolution assessment (Fig. 7) for East Africa. For the sake of comparison, this figure shows regional average change in yield derived from a coarse-resolution linear approach (done by reproducing crop yield estimates forced by GCM data (see Methods, Section 2.3 for details) compared to a dynamically downscaled regional climate model coupled to a process-based crop simulation model. The linear regression model $R^{2}$ was 0.24 ; while the regression coefficients were 3.81 for temperature, 0.0005 for rainfall, and $5 \times 10^{-5}$ for the cross-term. Each bar represents the average 


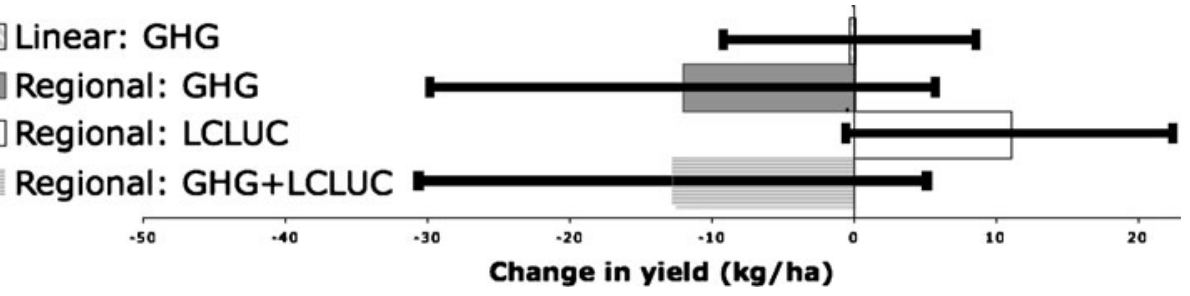

Fig. 7 Ranges of yield change variability comparing a linear statistical model versus integrated models that compare climate and land cover/use change. The top bar graph shows estimated GHGdriven yield change with a simple regression model; the middle bar graph shows an opposite response using regional process-based models; the third bar graph shows the effects of LCLUC using regional process-based models. Standard errors are (top) $\pm 8.9 \mathrm{~kg} / \mathrm{ha}$, (second) $\pm 17.8 \mathrm{~kg} / \mathrm{ha}$, (third) $\pm 11.5 \mathrm{~kg} / \mathrm{ha}$, and (bottom) $\pm 17.9 \mathrm{~kg} / \mathrm{ha}$

regional yield change from current to future conditions using the same GCM data. The error bars represent the standard errors for each ten-year sample. These two approaches are substantially different. That is, the coarse approach aggregates yield (or yield response) over large areas, assumes linear relationships between climate and yield, and tracks only the average values for the region. The fine-resolution approach is disaggregated to respond to spatial variability, explicitly calculates the nonlinear climate-yield relationships, and keeps an account of spatial variability in addition to national average yield values. In order to compare the regional simulations with the coarse model results, we aggregated finer resolution assessment results of this study to the national level, and compared the statistics of several countries together: Kenya + Tanzania + Rwanda + Burundi + Uganda.

As a result of these substantially different inputs and methods, the finer-resolution GHG forcings and LCLUC forcings show different responses (the lower three bar graphs) from one another and from the coarse-resolution approach (Fig. 7). The finer resolution approach of modeling of GHG effects produced a yield difference standard deviation of $176 \mathrm{~kg} / \mathrm{ha}$ (see Fig. 3f). Using the linear regression model as described in the Methods section, the yield difference standard deviation due to GHG would be $79 \mathrm{~kg} / \mathrm{ha}$ - much smaller. Standard deviation and standard error are key measures of variability; a lack of change in mean yields does not imply a lack of change in yield variability. Here, the mean values are different (though statistically no different from zero)-but more importantly, the variability is much greater for the regional experiments and better captures climate change effects than the coarseresolution approach (c.f. Thornton et al. 2009). Furthermore, aggregate expressions of yield change, in and of themselves (as in Fig. 7), are an incomplete description of yield changes and food risk; the spatial distribution and causative factors are also needed.

\section{Discussion}

This paper illustrates three important factors that need to be considered when making estimates of food production and risk due to future climate change. First, heterogeneous responses in yield can result from homogeneous climate drivers. 
Second, LCLUC can also significantly influence crop yield at a scale similar to GHG effects. Third, a process-based fine-resolution framework can produce different distributions of variability in yield. This third point has been shown before (e.g. Jones and Thornton 2003; Thornton et al. 2009) but it is an important element in determining risk-i.e., regional variability (and thus risk) is large and may be masked at coarse resolution. Since food production risk is primarily associated with the occurrence of extremes, a high-resolution approach exhibits much higher sensitivity to yield changes as well as much higher spatial variability.

We used a process-based deterministic crop model, driven by a deterministic regional climate model, with inclusion of two drivers of climate change. With models that incorporate process-based factors, some explanatory power is gained by looking at aspects like water stress or nitrogen stress, which are taken into account by the crop-climate model. This crop model is deterministic; thus a change in yield can be traced directly to the change in a climate variable (or variables) that caused the yield change. This is also true for linear regression models, but processed-based models allow us to examine causality as well as complex, nonlinear factors. For many climate changes, smaller percentage impacts (e.g. those less than 10\%) are simply not significant, particularly given all the possible errors involved. Even large changes in climate forcings-like a large increase in rainfall-may not be significant because of other factors (e.g. sandy soils or hot growing-season temperatures) that may be poorly handled by crop models. However, some significant changes do emerge even though the aggregate histograms in Figs. 3f and $4 \mathrm{f}$ center about zero. Comparing yield changes in Figs. $3 \mathrm{f}$ and $4 \mathrm{f}$, greater food production variability was obtained using this higher resolution approach that would not be evident using data aggregated to the national level (see Fig. 7). Furthermore, Fig. 7 only displays spatial variability, not inter-annual variability. The strength of a fine-resolution/regional approach is ultimately in its ability to identify regions and physical causes for elevated food production risk via localized trends in yield change, which could lead to more effective use of donor investments for alleviating hunger and poverty.

How much trust can be placed in these model results? Both the crop and climate models are limited in their abilities to reflect reality. These models are limited by the quality of the input data, their accuracies in parameterizing complex processes like turbulence or the grin-filling stage, and their outright non-use of factors like pests or subgrid-scale phenomena. Heterogeneity of our model responses is complicated too; since no spatially explicit data on crop yields in east Africa are available, it is very difficult to validate crop model yields except at aggregated (i.e., national) levels. Even then, national estimates in Uganda, Kenya and Tanzania are often based on very rough estimates for yields in more rural areas. Without good ground truth, it is quite possible that our model results could over-estimate the heterogeneity of the responses to the LCLUC and GHG forcings. However, these are processbased models. They have been built carefully and validated against ground truth in many locations. We can examine the reasons and causality for a change in yield. For example, if we examined maize yield near Mwanza, we can check the model to see that nitrogen stress is the reason for a given decline in the model. Thus, while the response heterogeneity could be overestimated, the responses are not "noise" or just a side effect of simple models forced by strong anomalies. The forcings are within reasonable range of actual weather values and they are broadly consistent with observed historical trends. The historical crop responses fall well within expected 
ranges for real maize yields in east Africa. Thus, the changes we see in the modeled yields broadly reflect possible changes caused by climate forcings from LCLUC and GHG. For further information on the limitations of these models, several model intercomparison projects (MIPs) that include RAMS are available that describe model shortcomings. For CERES, validation can be found in numerous publications including Jones et al. (2003).

These model projections are intended mainly to illustrate variability and the importance of LCLUC as a driver of yield change. Since the projections are peculiar to one particular future landscape and scenario, the specific patterns we find should not be used to plan adaptations. Rather, they can inform how we plan adaptations-by encouraging more spatially explicit measurements of climate trends in specific areas, by suggesting several pilot programs for different crop breeds, and by promoting more local (in-country) modeling of crop yields by scientists who are familiar with local trends, local breeds, and habits of local agriculture. The projections shown here do not have sufficient resolution or generalization to plan adaptations, but they do point to areas that may show climate sensitivity; these areas would benefit from more climate and crop monitoring.

We have demonstrated that high-resolution spatial characteristics (such as sandy soils, nitrogen inputs, etc) exert important constraints in understanding the system's climate shifts and resultant yield changes. These factors can play different roles under GHG forcings or LCLUC forcings. The context of projected yield change must be examined as well-for example, valuable cash crops like coffee and tea should not (and certainly will not) be abandoned in Kenya's highland areas merely because conditions are more suitable for a cereal crop. In the Kenya highlands, even a projected gain (of maize yield) is not necessarily enough to transform the agricultural systems there because farmers decide land use in a context of culture, economic forces, and sophisticated relationships within their societies. While our extreme case of massive LCLUC here ignored some socioeconomic constraints related to major protected areas (important for tourism), it was done to illustrate the sensitivity of certain areas.

Since our results show complex impacts, the ability of livelihood systems to adapt or mitigate climate change effects may depend on the character of the drivers most influential for the locality (e.g. Table 1) and the adaptive capacity of the human system in question. Thoughtful land use and land management could thus play a major role in coping with climate change and adapting human livelihood systems, such as decentralized ranching and shifts in crop production areas. We only investigated consequences for maize production; other impacts on human systems (e.g. water availability, livestock health, invasive species) may also reflect climate shocks with similar GHG, LCLUC, or coupled spatial responses. These are indicative of complex features and responses of the complex natural-human systems, warranting further study of savanna ecosystems.

Diffenbaugh et al. (2005) state "consideration of fine-scale processes is critical for accurate assessment of local- and regional-scale vulnerability to climate change." Our analysis reinforces this perspective. Addressing Objective II, we also show that future LCLUC is a first-order driver of yield change via modification of the surface energy budget (e.g. Seneviratne et al. 2006). Our results indicate that (1) crop yield can exhibit complex responses to broadly homogeneous climate forcings like elevated GHG influences, and (2) LCLUC-driven climate forcings are capable of 
driving yield changes similar in magnitude to GHG that also exhibit highly complex heterogeneous responses. The magnitude of the changes in yield modeled here are quite high, suggesting that LCLUC plays a critical role in food production risk. The choice of regional climate model can also strongly affect the outcomes of such studies, and this is an important element to consider in developing these types of studies (Oettli et al. 2011).

Quantifying the variability in yield plays a critical role in the assessment of food production risk -in turn a critical aspect of food security risk. From the perspective of sustainability and understanding agricultural productivity, it is important that donor institutions consider matters of land use, scale/resolution, heterogeneity, and representativeness when evaluating comparisons of responses in different regions or continents to climate change. Despite some drawbacks, process-based crop models might be used when appropriate to examine variability in regional food security risk and to understand which climate factors, including LCLUC, are of paramount importance to the farmers on the ground. Finally, and perhaps most importantly, we recommend that climate impacts of LCLUC be considered as a primary driver of food production risk.

Acknowledgements This work was funded by NSF Biocomplexity of Coupled Human and Natural Systems Program award BCS 0308420 and BCS/CNH 0709671. This research uses data provided by the Community Climate System Model project (www.ccsm.ucar.edu), supported by the Directorate for Geosciences of the National Science Foundation (NSF) and the Office of Biological and Environmental Research of the U.S. Department of Energy. Population data were provided by CIESIN (NASA Contract NAS5-03117). We also wish to thank David Campbell, Amelie Davis, Deepak Ray, and Joseph Maitima for their contributions to this work.

Open Access This article is distributed under the terms of the Creative Commons Attribution Noncommercial License which permits any noncommercial use, distribution, and reproduction in any medium, provided the original author(s) and source are credited.

\section{References}

Africover (2002) Africover-Eastern Africa module. Land cover mapping based on satellite remote sensing. Food and Agriculture Organization of the United Nations. Available at http://www.africover.org/download/documents/Short_Project_description_en.pdf

Allard J, Carleton AM (2010) Mesoscale associations between midwest land surface properties and convective cloud development in the warm season. Phys Geogr 31:107-136

Anyah RO, Semazzi FHM (2007) Variability of East African rainfall based on multiyearRegCM3 simulations. Int J Climatol 27:357-371

Anyah RO, Semazzi FHM, Xie L (2006) Simulated physical mechanisms associated with climate variability over Lake Victoria basin in East Africa. Mon Weather Rev 134:3588-3609

Batjes NH, Bridges EM (1994) Potential emissions of radiatively active trace gases from soil to atmosphere with special reference to methane: development of a global data base (WISE). J Geophys Res 99(D8)16:479-489

Black E (2005) The relationship between Indian Ocean sea-surface temperature and East African rainfall. Philos Trans R Soc A 363(1826):43-47

Black E, Slingo J, Sperber KR (2003) An observational study of the relationship between excessively strong short rains in coastal east Africa and Indian ocean SST. Mon Weather Rev 131:74-94

Boko M, Niang I, Nyong A, Vogel C, Githeko A, Medany M, Osman-Elasha B, Tabo R, Yanda P (2007) Africa: climate change 2007: impacts, adaptation and vulnerability. In: Parry ML, Canziani OF, Palutikof JP, van der Linden PJ, Hanson CE (eds) Contribution of working group II to the 
4th assessment report of the intergovernmental panel on climate change. Cambridge University Press, Cambridge, pp 433-467

Boote KJ, Sinclair TR (2006) Crop physiology: significant discoveries and our changing perspective on research. Crop Sci 46:2270-2277

Boote KJ, Jones JW, Pickering NB (1996) Potential uses and limitations of crop models. Agron J 88:704-716

Boote KJ, Allen LH, Vara Prasad Jr PV, Jones JW (2010) Testing effects of climate change in crop models. In: Hillel D, Rosenzweig C (eds) Handbook of climate change and agroecosystems. Imperial College Press, London, pp 109-129

Boyer JS (1982) Plant productivity and environment. Science 218:443-448

Burke MB, Lobell DB, Guarino L (2009) Shifts in African crop climates by 2050, and the implications for crop improvement and genetic resources conservation. Glob Environ Change 19(3):317-325

Camberlin P, Philippon N (2002) The East African March-May rainy season: associated atmospheric dynamics and predictability over the 1968-97 period. J Climate 15:1002-1019

Charney J, Quirk WJ, Chow S, Kornfield J (1977) A comparative study of the effects of albedo change on drought in semi-arid regions. J Atmos Sci 34:1366-1385

Collins WD, Bitz CM, Blackmon ML, Bonan GB, Bretherton CS, Carton JA, Chang P, Doney SC, Hack JJ, Henderson TB, Kiehl JT, Large WG, McKenna DS, Santer BD, Smith RD (2006) The community climate system model: CCSM3. J Clim 19:2122-2143

Cotton WR, Coauthors (2003) RAMS 2001: current status and future directions. Meteorol Atmos Phys $82: 5$

Diffenbaugh N, Pal JS, Trapp RJ, Giorgi F (2005) Fine-scale processes regulate the response of extreme events to global climate change. Proc Natl Acad Sci USA 102(44):15774-15778

FAO (Food and Agriculture Organization of the United Nations) (1978) Report on the agroecological zones project-volume 1: methodology and results for Africa. FAO, Rome Italy. World Soil Resources Project 48, p 158

FAO (Food and Agriculture Organization of the United Nations) (1995) Digital soils map of the world and derived soil properties V 3.5. Land and Water Digital Media Series 1, FAO, Rome

Feddema JJ, Oleson KW, Bonan GB, Mearns LO, Buja LE, Meehl GA, Washington WM (2005) The importance of land cover change in simulating future climates. Science 310:1674

Funk C, Senay G, Asfaw A, Verdin J, Rowland J, Korecha D, Eilerts G, Michaelsen J, Amer S, Choularton R (2005) Recent drought tendencies in Ethiopia and equatorial-subtropical Eastern Africa. Famine early warning network and US Agency for International Development, Washington, $\mathrm{p} 15$

Funk C, Dettinger M, Michaelsen J, Verdin J, Brown M, Barlow M, Hoell A (2008) Warming of the Indian Ocean threatens eastern and southern African food security but could be mitigated by agricultural development. Proc Natl Acad Sci USA 105:11081. doi:10.1073/pnas.0708196105

Gijsman AJ, Thornton PK, Hoogenboom G (2007) Using WISE database to parameterize soil inputs for crop simulation models. Comput Electron Agric 56:85-100

Hay R, Porter JR (2006) The physiology of crop yield, 2nd edn. Blackwell, Oxford, p 328. ISBN 9781405108591

Hijmans, RJ, Cameron SE, Parra JL, Jones PG, Jarvis A (2005) Very high resolution interpolated climate surfaces for global land areas. Int J Climatol 25:1965-1978

Hulme M, Doherty R, Ngara T, New M, Lister D (2001) African climate change: 1900-2100. Clim Res 17:145-168

ICASA (2007) The International Consortium for Agricultural Systems Applications website. Available at http://www.icasa.net/index.html

Jones PG, Thornton PK (2000) MarkSim: software to generate daily weather data for Latin America and Africa. Agron J 92(2000):445-453

Jones PG, Thornton PK (2003) The potential impacts of climate change on maize production in Africa and Latin America in 2055. Glob Environ Change 13:51-59

Jones JW, Hoogenboom G, Porter CH, Boote KJ, Batchelor WD, Hunt LA, Wilkens PW, Singh U, Gijsman AJ, Ritchie JT (2003) The DSSAT cropping system model. Eur J Agron 18:235-265

Kain JS, Fritsch JM (1993) Convective parameterization for mesoscale. models: the Kain-Fritsch scheme. Meteorol Monogr 24:165

Li Z, Mölders N (2008) Interaction of impacts of doubling $\mathrm{CO}_{2}$ and changing regional land-cover on evaporation, precipitation, and runoff at global and regional scales. Int J Climatol 28:1653-1679

Livermore MTJ, Parry ML, Rosenzweig C, Iglesias A, Fisher G (2003) Global food security and the IPCC SRES: assessing the threat from climate change in several equi-plausible worlds. Glob Environ Change 14:3-20 
Lobell D, Field C (2007) Global scale climate-crop yield relationships and the impacts of recent warming. Environ Res Lett 2:014002

Lobell D, Burke M, Tebaldi C, Mastrandrea M, Falcon W, Naylor R (2008) Prioritizing climate change adaptation needs for food security for 2030. Science 319:607-610

Lofgren BM (1995) Surface albedo-climate feedback simulated using two-way coupling. J Clim 8:2543-2562

Maynard K, Royer J-F (2004) Effects of "realistic" land-cover change on a greenhouse-warmed African climate. Clim Dyn 22:343-358. doi:10.1007/s00382-003-0371-z

Moore N, Torbick N, Pijanowski B, Lofgren B, Wang J, Kim D-Y, Andresen J (2009) Adapting MODIS-derived LAI and fractional cover into the RAMS model for East Africa, in revision at International Journal of Climate

Mundia CN, Aniya M (2005) Analysis of land use changes and urban expansion of Nairobi City using remote sensing and geographical information systems. Int J Remote Sens 26(13):2831-2849

Mutai CC, Ward MN (2000) East African rainfall and the tropical circulation/ convection on intraseasonal to interannual timescales. J Clim 13:3915-3939

Neilson RP, Drapek RJ (1998) Potentially complex biosphere responses to transient global warming. Glob Chang Biol 4:505-521

Oettli P, Sultan B, Baron C, Vrac M (2011) Are regional climate models relevant for crop yield prediction in West Africa? Environ Res Lett 6:014008

Ogallo LA (1989) The spatial and temporal pattern of the East African seasonal rainfall derived from principal component analysis. Int J Climatol 9:145-167

Olson JM, Misana SM, Campbell DJ, Mbonile MJ, Mugisha S (2004) The spatial pattern and root causes of land use change in East Africa. LUCID Working Paper 47, International Livestock Research Institute, Nairobi, Kenya

Olson JM, Alagarswamy G, Andresen JA, Campbell DJ, Davis AY, Ge J, Huebner M, Lofgren BM, Lusch DP, Moore NJ, Pijanowski BC, Qi J, Thornton PK, Torbick NM, Wang J (2007) Integrating diverse methods to understand climate-land interactions in East Africa. Geoforum. doi:10.1016/j.geoforum.2007.03.011

Parry M (1990) The potential impact on agriculture of the greenhouse effect. Land Use Policy 7:109_ 123

Parry M, Rosenzweig C, Iglesias A, Fischer G, Livermore M (1999) Climate change and world food security: a new assessment. Glob Environ Change 9:51-67

Parry ML, Rosenzweig C, Iglesias A, Livermore M, Fischer G (2004) Effects of climate change on global food production under SRES emissions and socio-economic scenarios. Glob Environ Change 14:53-67. doi:10.1016/j.gloenvcha.2003.10.008

Pielke RA, Marland G, Betts RA, Chase TN, Eastman JL, Niles JO, Niyogi DDS, Running SW (2002) The influence of land-use change and landscape dynamics on the climate system: relevance to climate-change policy beyond the radiative effect of greenhouse gases. Philos Trans $\mathrm{R}$ Soc Lond, Ser A 360:1705-1719

Pielke Sr RA, Adegoke J, Beltran-Przekurat A, Hiemstra CA, Lin J, Nair US, Niyogi D, Nobis TE (2007) An overview of regional land-use and land-cover impacts on rainfall. Tellus 59B:587-601

Pijanowski B, Brown D, Shellito B, Manik G (2002) Using neural networks and GIS to forecast land use changes: a land transformation model. Comput Environ Urban Syst 26:553-575

Pijanowski B, Pithadia S, Shellito B, Alexandridis K (2005) Calibrating a neural network-based urban change model for two metropolitan areas of the Upper Midwest of the USA. Int J Geogr Inf Sci 19:197-215

Pijanowski B, Davis A, Robinson K (2009) Error propagation in coupled regional land-climate models: 1. Quantifying aggregate spatial errors from a land change model to a regional atmospheric model. In Revision at IJGIS

Ritchie JT, Singh U, Godwin DC, Bowen WT (1998) Cereal growth, development and yield. In: Tsuji GY, Hoogenboom G, Thornton PK (eds) Understanding options for agricultural production. Kluwer, Dordrecht, pp 79-98

Rosegrant MW, Co-Authors (2005) Looking ahead: long term prospects for Africa's agricultural development and food security. International Food Policy Research Institute, Washington, DC

Semazzi FHM, Song Y (2001) A GCM study of climate change induced by deforestation in Africa. Clim Res 17:169-182

Seneviratne SI, Lüthi D, Litschi M, Schär C (2006) Land-atmosphere coupling and climate change in Europe. Nature 443:205-209

Serneels S, Linderman M, Lambin EF (2007) A multilevel analysis of the impact of land use on interannual land-cover change in East Africa. Ecosystems 10:402-418 
Thornton PK, Jones PG, Owiyo T, Kruska RL, Herrero M, Orindi V, Bhadwal S, Kristjanson P, Notenbaert A, Bekele N, Omolo A (2008) Climate change and povert in Africa: mapping hotspots of vulnerability. African Journal of Agricultural and Resource Economics 2(1):24-44

Thornton PK, Jones PG, Alagarswamy G, Andresen J (2009) Spatial variation of crop yield response to climate change in East Africa. Glob Environ Change 19:54-65

Tiffin R, Xavier I (2006) Is agriculture the engine of growth? Agric Econ 35:79-89

Torbick N, Lusch D, Qi J, Moore N, Olson J, Ge J (2006) Developing land use/land cover parameterization for climate and land modelling in East Africa. Int J Remote Sens 27(19):4227-4244

United Nations, Department of Economic and Social Affairs, Population Division (2007) World population prospects: the 2006 revision. United Nations publications, ST/ESA/ SER.A/266

Walko R, Coauthors (2000) Coupled atmosphere-biophysics-hydrology models for environmental modeling. J Appl Meteorol 39:931

Wang J, Yang L (2007) Efficient and fast spline-backfitted kernel smoothing of additive models. Ann Inst Stat Math. doi:10.1007/s10463-007-0157-x 